\title{
TOLIVAR ALAS, L., Parlamento y Universidad: Los senadores por la Universidad de Oviedo, Servicio de publicaciones, Universidad de Oviedo, 2019.
}

La Apertura de Curso, que declara inaugurado oficialmente el año académico, constituye uno de los eventos más solemnes de la Universidad. En Oviedo además conserva toda una serie de símbolos tradicionales y a él acuden los miembros del Claustro revestidos con el traje académico, además de otros miembros de la institución académica y numerosas autoridades civiles.

Tras la llegada de una nutrida y multicolor comitiva académica y la lectura de la memoria del curso anterior realizada por el Secretario General, se da paso como elemento central del acto a la Lección Inaugural, que corre a cargo del profesor designado por la Facultad o Escuela de la Universidad a la que corresponda ese año, según el orden establecido de antigüedad de los centros. Así, las Facultades y Escuelas se ordenarán por la antigüedad de su creación formal, desde la más antigua a la más moderna. La fecha de creación será la que se corresponda con la norma o acto jurídico acreditado en el que se proceda a la creación oficial del centro de que se trate. En caso de coincidencia en la fecha de creación, se seguirá el orden del acto o decreto de creación. En caso de segregación, fusión o refundación o cambio de estatus, las Facultades o Escuelas resultantes se considerarán de nueva creación.

Siguiendo los referidos criterios, la Facultad de Derecho resulta la primera de la lista, y a su profesorado le ha correspondido dictar la Lección Inaugural ya en trece ocasiones desde el curso 1939/1940, actuando como ponentes profesores de la talla iuspublicista de Teodoro González García o Sabino Álvarez Gendín. El número doce más uno correspondía, en el curso 2012/2013, al hoy emérito profesor Ramón Punset Blanco, quien disertó sobre "La reforma de la Constitución. Aporías del cambio constitucional en el derecho español". La actualidad del tema resulta evidente y debe ser doblemente celebrada; no ha de resultar fácil elegir materia sobre la que impartir lección a toda la comunidad universitaria, pues pocas veces puede verse tal nivel multidisciplinar en un solo salón, que por cierto ha pasado de ser el Paraninfo a la Biblioteca Universitaria. Se ha buscado una ubicación con mayor capacidad para acoger a una comunidad que también está en expansión, formada hoy por dieciséis centros frente a los cinco con que contaba al terminar los años setenta. Cierto es que algunos no se resisten a realizar su propia inauguración de curso, con ponentes afectos a sus áreas de conocimiento, pero la inauguración solemne resulta por eso mismo una celebración mucho más transversal y plantea el reto innegable de tratar de interesar a la más variopinta colección de colegas. 
El 10 de septiembre de 2019 el testigo era recogido por mi maestro, el profesor Tolivar Alas. Tan sólo siete años más tarde de la última Lección jurídica, el honor volvía a recaer en la Facultad de Derecho, por los caprichosos azares de un régimen transitorio que alteró el orden de lectura que ya se ha referido a fin de ajustarlo a los cambios introducidos en la configuración y denominación de los centros tras la implantación del Espacio Europeo de Educación Superior. La Facultad, cuyo equipo directivo circunstancialmente integro en estos momentos, designa para la Lección Inaugural al profesor en activo más antiguo y ese resultó ser el profesor Tolivar. No es sin embargo el de mayor edad, ni el de arraigo anterior en la "casa", pues antes que en Oviedo (1992), fue catedrático de Derecho Administrativo en Murcia (1987) y León (1989); un doble mérito, ejemplar frente a la posverdad de la endogamia, los cotos vedados y los acomodos universitarios.

El tema para su Lección fue "Parlamento y Universidad: los Senadores por la Universidad de Oviedo". Con él buscaba implicar a doctos y legos en un empeño al que lleva tiempo dedicando sus esfuerzos: la reposición de la documentación que esta institución perdió con la quema de octubre de 1934 y que, con un trabajo minucioso de búsqueda en otros archivos, podría compensarse. Al mismo tiempo desvelaba la estrecha relación que entre el Parlamento y las Universidades existió en determinados momentos de nuestra historia.

El trabajo se inicia así con un primer apartado introductorio, donde se da cuenta de los antecedentes de la participación de representantes de las Universidades españolas en los órganos legislativos y de su evolución, desde la Constitución de Cádiz a la de 1978. A continuación, se acomete un ágil e interesante repaso por las distintas elecciones a senador por la Universidad de Oviedo entre los años 1877 y 1923. La trascendencia del período elegido queda explícitamente justificada en el texto escrito de la Lección, dándonos el profesor Tolivar ejemplos sobresalientes de la crucial actividad de aquellos senadores, que participaron en la culminación de la codificación, la aprobación de las longevas Leyes de Enjuiciamiento Civil y Criminal del siglo XIX, la recepción de la doctrina del dominio público o la Ley de Santamaría Paredes en materia contencioso-administrativa.

Hasta 1903 el autor contó para su labor de recuperación documental con la guía de la Historia de la Universidad de Oviedo y noticias de los establecimientos de su Distrito del entonces Vicerrector y cronista oficial de Oviedo, a la postre Rector, don Fermín Canella Secades; de esa fecha en adelante, el rescate del profesor Tolivar tuvo que caminar de manera autónoma. Con todo, el autor no se limita a ofrecer meros datos, sino que realiza análisis certeros y relata divertidas y ácidas anécdotas propias de las miserias inherentes a un colegio electoral tan reducido como el del claustro de la Universidad de Oviedo en aquella época. Algo de imperecedero debe 
haber en ello, no obstante, a juzgar por las sonrisas que más de una vez el relato generó ante el actual y nutrido claustro de compañeros.

La Lección termina con una invitación a continuar en este tipo de investigaciones, guante que se lanza también a otras disciplinas, y se completa con un valioso anexo que reproduce las actas originales de escrutinio de las elecciones a senador por la Universidad de Oviedo en los 23 últimos años del siglo XIX y los primeros 23 del $\mathrm{XX}$, junto a otros censos de interés e información complementaria, procedentes del archivo de la Cámara Alta.

Con la sensibilidad histórica, artística y científica de su autor, y su solidez como estudioso del Derecho público, la Lección no sólo completa el acervo documental de la Universidad de Oviedo, sino que pone el foco sobre una faceta social de la institución ignota para muchos y de auténtica transferencia del conocimiento.

\author{
Alejandra Boto Álvarez \\ Profesora Titular de Derecho Administrativo \\ Universidad de Oviedo
}

